\section{ESA can be a society for all ecologists}

$\mathrm{F}_{\text {ec }}^{\text {or }}$ or nearly a century, the Ecological Society of America (ESA) has served as the professional home for ecologists. As long-standing members of ESA, we feel that two critical problems currently face the Society. The first challenge is in attracting and retaining members whose careers are outside of research. The second is that many existing members who are interested in engaging in policy or who would like to pursue a career outside of academia lack the necessary training and networking opportunities to do so.

Despite considerable changes over the years, ESA remains a largely academically oriented organization: $70 \%$ of its members are university researchers, professors predominate on its Governing Board, the editorial boards of ESA journals are composed mainly of university researchers, and its annual meetings are primarily geared toward academic attendees. But for the past decade or so, changes have been afoot that merit our collective attention.

One such change is the transformation in the landscape of universities and colleges. Competition for academic appointments is fierce, putting such positions increasingly out of reach for many early career ecologists who are being pushed by necessity into other professions. But many young ecologists are by choice pursuing careers outside academia. These ecologists want to work in arenas where they can help make a difference in the management and policy strategies that affect natural resources and other environmental concerns. Similarly, an increasing number of university ecologists would like to play a more meaningful role in decision making. While some academics have successfully made connections with decision makers in both the public and private sectors, many do not have the skill set or working knowledge to function effectively in these spheres.

Although they make up only a small percentage of its membership, ESA does have members who work for federal and state government agencies, nongovernmental organizations (NGOs), and private sector entities. These scientist-practitioners have the experience and professional networks that could help their academic colleagues gain traction in policy engagement and open doors for young ecologists. Additionally, many scientist-practitioners routinely seek the expertise of their university counterparts. Working together, ecological scientist-practitioners and research scientists can be a powerful force, and we believe we need to find ways to bring them together and enhance the value of the Society for ecologists in professions outside universities.

Society leaders can diversify ESA's elected Governing Board by encouraging nonacademic nominations. The Board determines ESA's mission and programs and would be enriched by voices from other sectors. Broader representation would foster new discussions, expand the Society's networks, and enhance our ability to make important decisions affecting future directions of ESA. Society leaders and other members can encourage committee chairs to invite practitioners to serve on their committees. A cross-section of professional ecologists should be actively engaged in our public affairs, science, diversity and education, meetings, awards, and publications committees, and the Society's journals would also benefit from editorial boards with a broader representation. Particularly when topics touch on policy and science communication, the participation of ecologists experienced in these areas would be a great advantage. Finally, we should encourage more practitioner-relevant content as well as offer further professional development opportunities at ESA's annual meetings.

There are some positive signs. ESA's fall election included candidates from federal agencies and NGOs, and in January the nominations committee - under the leadership of Past President Scott Collins - sent a request to all members encouraging nominations for Governing Board positions that "represent the human and institutional diversity of the ecological profession". The Society is also experimenting with more creative meeting formats and offering additional career-oriented training and mentoring. For example, a workshop led by Phyllis Thibodeau, a professional career coach, at the 2013 Annual Meeting provided students and early career ecologists with hands-on exercises to help articulate their life and career values, to interact with ecologists in a variety of careers, and to discuss the challenges of pursuing ecological careers outside research institutions. Moreover, a new Society initiative will offer an online network and resources for those seeking guidance in a range of careers.

We believe ESA members should think about how to leverage their respective skills, knowledge, and experiences to accomplish individual goals and enhance the collective strength of the ecological community. As ESA Past President Steward Pickett said recently: "A diversity of people and perspectives plays just as important a role in advancing sustainability as biological diversity does in sustaining an ecosystem".

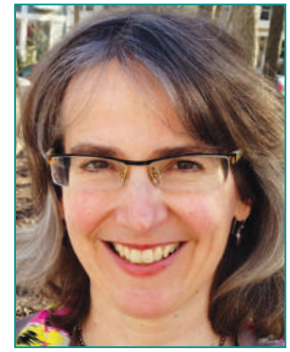

Nadine Lymn

Former ESA Director of Public Affairs

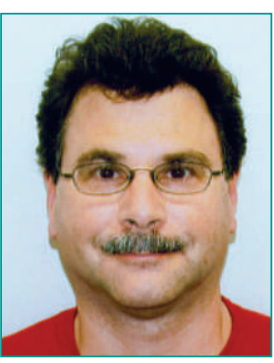

Richard V Pouyat

Former ESA VP for

Public Affairs

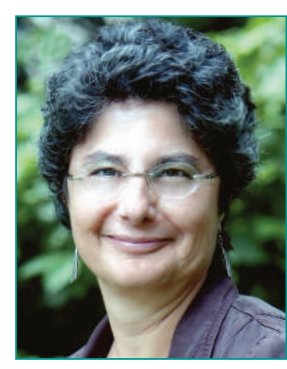

Deborah Goldberg Former ESA VP for Science and Professor, University of Michigan

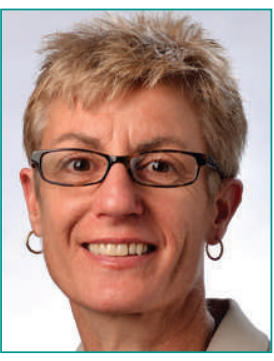

Sharon Collinge ESA VP for Public Affairs and Professor, University of Colorado 